\title{
Un poeta novísimo: Aldo Vásquez
}

Recibido: 16/01/2017 / Aceptado: 25/01/2017

Por Anastasio Lovo ${ }^{1}$

Aldo Vásquez (Managua, 1992) es uno de los poetas más destacado de las últimas promociones de escritores nicaragüenses. A los 24 años de edad obtuvo el Premio Leonel Rugama de Poesía Joven que otorga el Instituto Nicaragüense de Cultura. Actualmente se está graduando en Lengua y literatura hispánica en la UNAN Managua y ha pertenecido al Taller de Poesía del Centro Nicaragüense de Escritores y de la UNAN Managua.

Vásquez es dueño de un acabado poético pulcro, económico e irónico, que devela el mundo de un joven poeta. Un mundo marcado por las huellas del amor y el desamor, de la mesura y los excesos, de la alegría de vivir y la angustia frente a la sucia realidad heredada por los mayores. A esta crudeza existencial, Vásquez la sortea con los pases, fintas y verónicas de la cultura para impedir que el agua llegue a la piel, la sangre al río o la cerveza a la cabeza.

Aldo Vásquez alimenta su poesía de los maestros nicaragüenses, de autores iberoamericanos, norteamericanos, franceses, alemanes o rusos, sin engolarse con la cultura literaria ya que nunca la congela estatua. Existe una vertiente corrosiva y feliz en la poesía de Vásquez, originada en una vena antipoética, parriana, muy sutil y elegante.

Vásquez no es poeta de repeticiones, más de una vez encuentra su voz en sus poemas, pero estoy seguro que siempre le seducirán nuevas ramas, paisajes, amores y mares, donde ensayar nuevos cantos como el ruiseñor de Keats.

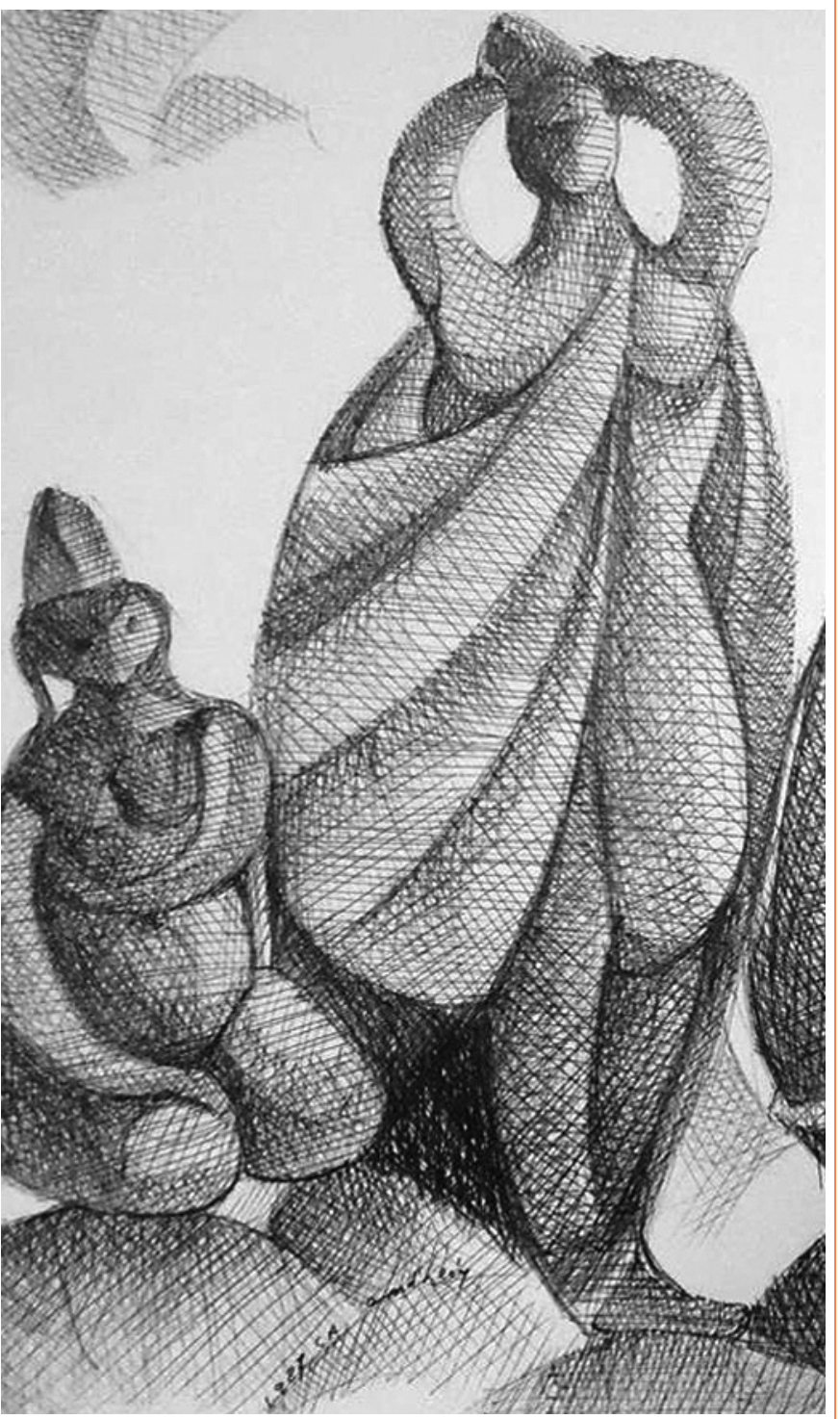

Autor: Omar d’León.

1 Poeta y escritor nicaragüense. Presidente Honorario del Centro Nicaragüense de Escritores (CNE). 


\section{Literatura}

\section{Poemas de Aldo Vásquez}

\section{Soy Veltchaninov}

Mi nariz irrumpe las calles

soy rata en la despensa

devorando hectáreas de soledad

bebo a cántaros mi egoísmo e

injurio a las esposas

despojo al melancólico de sus vástagos.

Reclamo tedio, soga, dolor

flema,miedo, juguetes, fiebre.

Busco a tientas en cantinas

Soy croquis de homicidio impune

$$
\text { albergues, cementerios. }
$$

cargando un pequeño féretro

mientras merodeo por las calles.

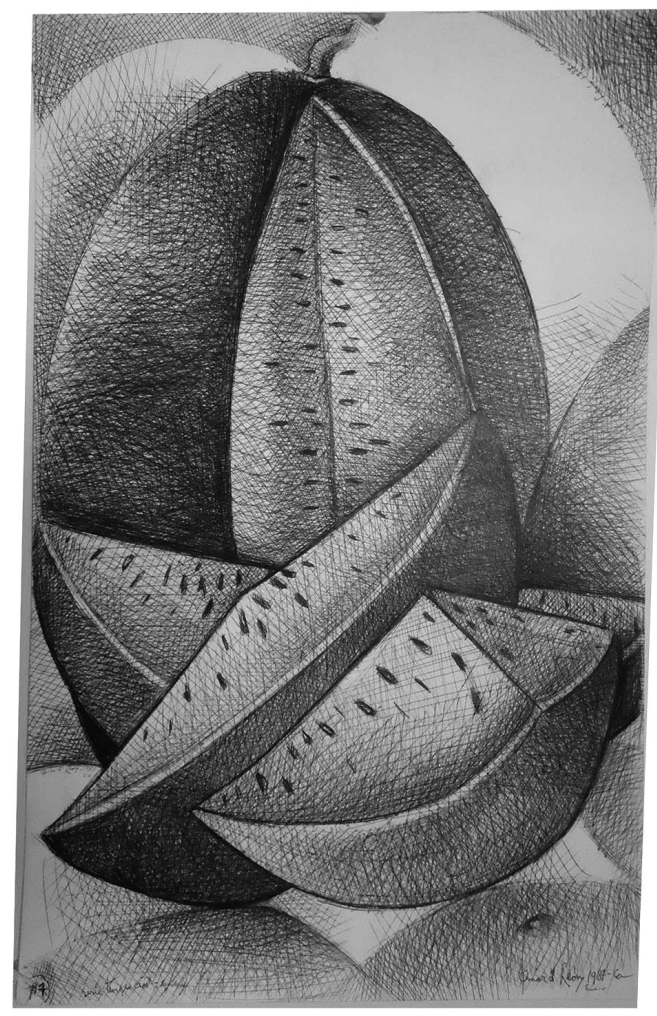

Autor: Omar d’León.

\section{Una canción para Sabina}

Una canción para Sabina

deberá estar a la altura de la crítica

y ser impúdica como el objeto de homenaje.

Debe escucharse cuando se rompan sus tendones $y$ las cuerdas lo asfixien.

El desamor habrá perdido su más fiel pregonero los bufones tenderán alambres de púas, Madrid será negra telaraña y las nubes seda enmohecida. Una canción para Sabina debe escucharse mientras se toma un whisky on the rocks con un ángel sin alas en la barra de San Pedro.

\section{Reproche a Judas Iscariote}

¿Acaso pretendés borrar las huellas de tu romería? El eco de tus pasos

Aúlla en cada ausencia del sol.

Ni lauros o éxodos

Ni carcajadas, oraciones o monedas

Pueden atiborrarte de paz.

La saliva te repudia

\section{Las sandalias huyen}

En $G$ ó $l$ l g Homicida fraternal

¿De qué te sirve ser sagaz

Si caés de bruces en la misma charca?

¿Por qué mendigar espejismos al espejo

Y ser faro de luz inconstante

En la tempestad soberbia?

¿Por qué no esperaste de la mano el calor

$Y$ cediste al frio de la cuerda? 


\section{Literatura}

\section{Para sanar tu cuerpo}

Hace falta un lecho de agua

sumergirme en tu perfil de nieve

en el trinar de huesos y labios

que se desliza bajo mi nombre.

Bebo, lamo, muerdo caracolas

tomo tus párpados, tu cintura.

Para salvarte del verdugo

que te persigue en un carruaje sepia.

Debo sepultarte bajo espuma

y embalsamarte con mi sudor.

\section{Esquirlas de ángel}

Una noche, cansado de trastabillar

me deslicé por la durmiente madrugada



Autor: Omar d'León.

\section{Nostalgia a destiempo}

\section{Y que de nada sirva los ojos restregarse Cuando todo se quemó junto con tus labios.}

me libré de esposas imperceptibles al ojo incauto.

Robé el velo de estrellas y lo vendí a salamandras videntes.

La vendimia y sequía vibraron bajo mis pies.

Entonces, prendí fuego a mi coraza mortal:

Hilo y cabello

córneas y ojales

uñas y cadenas

dedos y cordones

fundidos en rocío.

¿Por qué contemplar tu iris marchita

Borís Pasternak

debajo de mis párpados o

frotar la cicatriz

que me dejó tu cuerpo

una noche de noviembre

en el campus universitario?

La ciudad acecha con

semáforos de hojas grises

migajas de porcelana

Expandido entre partículas de ceniza

paredes que apretujan - como tus piernas -

recordé acertados azares

$y$ las raíces marchitas que amputé de mis pies.

las esquirlas de un ángel

que me salvó del abismo de barro.

Sólo me queda reptar por

la madrugada sin luna

entre restos de botellas

$y$ veleros disecados. 


\section{Literatura}

\section{Los acantilados}

En los acantilados

los guiños, trenes, cielos, playas, anillos y palabras

se vuelven milimétricos objetos olvidados.

silban corrientes

cálidas-lacerantes y afelpadas-frías.

Consumen luz y sombras, locura y temores.

Sólo queda en las manos

la nariz de un perro buscando sin cesar.

El acantilado es mayor entre dos sombras y

la precisión de todos sus desaciertos.

Dos cuerpos incapaces de sanar

vagan por andenes paralelos.

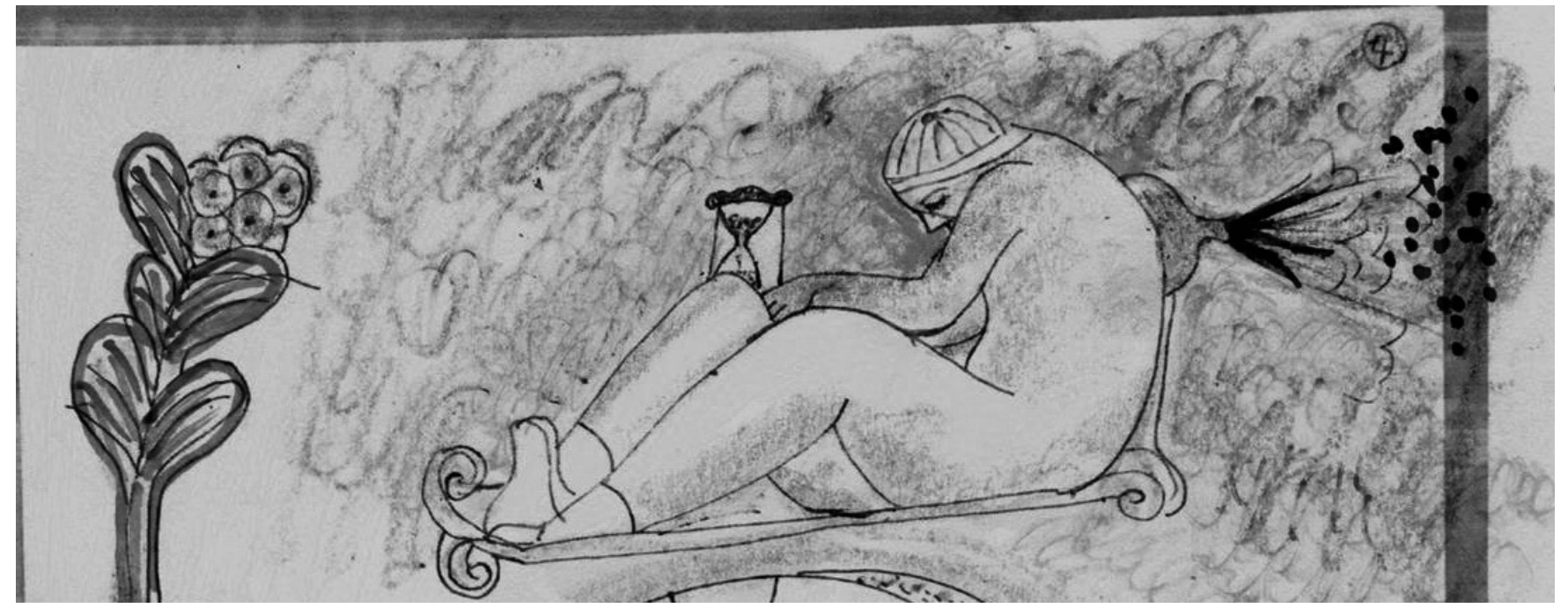

Autor: Autor: Omar d’León. 